1 Identification and characterization of two transmembrane proteins

2 required for virulence of Ustilago maydis

\title{
3 Paul Weiland ${ }^{1}$, Florian Altegoer ${ }^{1,2^{*}}$
}

$4 \quad{ }^{1}$ Philipps-University Marburg, Center for Synthetic Microbiology (SYNMIKRO) \& Faculty of

5 Chemistry, Hans-Meerwein-Strasse C07, 35043, Marburg, Germany

${ }^{2}$ Max-Planck Institute for terrestrial Microbiology, Max-von-Frisch-Straße 10, Marburg, Germany

* Correspondence:

8 Florian Altegoer

9 altegoer@uni-marburg.de

10 Keywords: Ustilago maydis, membrane protein, virulence, biotrophy, mass photometry, mistics

\section{Abstract}

Smut fungi comprise a large group of biotrophic phytopathogens infecting important crops such as wheat and corn. Through the secretion of effector proteins, the fungus actively suppresses plant immune reactions and modulates its host's metabolism. Consequently, how soluble effector proteins contribute to virulence is already characterized in a range of phytopathogens. However, membraneassociated virulence factors have been much less studied to date. Here, we investigated six transmembrane (TM) proteins that show elevated gene expression during biotrophic development of the maize pathogen Ustilago maydis. We show that two of the six proteins, named Vmp1 and Vmp2 (virulence-associated membrane protein), are essential for the full virulence of $U$. maydis. The deletion of the corresponding genes lead to a substantial attenuation in the virulence of $U$. maydis. Furthermore, both are conserved in various related smuts and contain no domains of known function. Our biochemical analysis clearly shows that Vmp1 and Vmp2 are membrane-associated proteins, potentially localizing to the $U$. maydis plasma membrane. Mass photometry and light scattering suggest that Vmp1 mainly occurs as a monomer, while Vmp2 is dimeric. Notably, the large and partially unstructured C-terminal domain of Vmp2 is crucial for virulence while not contributing to dimerization. Taken together, we here provide an initial characterization of two membrane proteins as virulence factors of $U$. maydis.

\section{Introduction}

An increasing number of infectious diseases are threatening agricultural and natural systems. This development results in large crop losses, with up to $20 \%$ of maize harvest loss caused by fungal pathogens such as Ustilago maydis (Fisher et al. 2012). Despite the high number of fungal species infecting plants, only a few fungal plant pathogen systems allow the physiological, molecular, and biochemical investigation of both host and parasite (Dean et al. 2012; Giraldo and Valent 2013). Among those, the smut fungus $U$. maydis represents an excellent case to study the infection process. Smut fungi are a large group of biotrophic parasites with currently more than 1500 described species infecting mostly grasses, including important cereal crops such as maize, wheat, barley, and sugar cane (Zuo et al. 2019). The host of U. maydis is the sweet corn Zea mays, where it can infect all aerial parts of the plant and establishes a biotrophic interface with its host cells. 
Biotrophy implies the formation of a tight interaction zone between host and fungal intruder that allows for the exchange of signals and nutrients without initiating apoptosis of host cell tissue. Biotrophic pathogens need to maintain their respective host's viability in order to complete their life cycle. Therefore, $U$. maydis suppresses defense responses, manipulates the metabolism of host cells, and alters their proliferation-rate, ultimately leading to the formation of large spore-filled tumors in the infected tissue (Zuo et al. 2019). The secretion of a variety of effector proteins plays a critical role during this process (Lanver et al. 2017). Effector proteins can be grouped in apoplastic effectors, which remain in the apoplastic space between plant and fungal cells, and cytoplasmic effectors that are further translocated into the host cells' cytoplasm (Mueller et al. 2008).

This molecular warfare is not restricted to the apoplastic space or the cytosol of host cells. Instead, pathogenic development and tumor formation are accompanied by a thorough remodeling of both plant and fungal cell walls (Matei et al. 2018). These processes support fungal development as the breakdown and import of carbohydrates derived from the host are important sources of carbon for the fungus during growth (Sosso et al. 2019). Sugar sensing and its uptake have thus gained more attention in $U$. maydis in recent years, leading to the identification of several transporters essential for virulence (Wahl et al. 2010; Schuler et al. 2015). The genome of $U$. maydis encodes more than 19 sugar transporters, and most of them are upregulated during pathogenic development (Sosso et al. 2019). Consequently, plants have evolved mechanisms to detect and deplete apoplastic sugar concentrations to hinder fungal growth and activate immune responses (Lemoine et al. 2013; Morkunas and Ratajczak 2014). While these examples are among the first transmembrane proteins studied in the infection context, they also highlight the relevance of membrane-embedded proteins during virulent growth of smut fungi.

However, there is little known on specialized membrane proteins involved in signaling, stimuli recognition, and thus establishing a compatible interaction with the respective host plants. In one case, the membrane protein Pit1, encoded within the pit (protein important for tumors) gene cluster, is required for tumor formation (Doehlemann et al. 2011). It has been reported to localize to hyphal tips, although the precise molecular function remains unclear.

Here, we have analyzed a set of six genes showing elevated expression levels during pathogenic development of $U$. maydis (Lanver et al. 2018) encoding proteins that harbor predicted transmembrane helices. Of those two show a strong attenuation in virulence upon deletion of their respective genes. Therefore, we name these proteins Vmp1 and Vmp2 for virulence-associated membrane protein and present a biochemical characterization giving insights into their molecular architecture and suggesting a potential role during virulence of $U$. maydis.

\section{Material and Methods}

Molecular cloning of expression plasmids. For the plasmid constructions, standard molecular cloning strategies and techniques were applied (Sambrook J, Fritsch EF 1989). All plasmids and primers used in this study are listed in tables $\mathbf{S 1}$ and $\mathbf{S 2}$. For the overproduction of the C-terminal domain (CTD) of Vmp2, the plasmid pEMGB1-vmp2 CTD was generated. The overproduced protein will be fused to the solubility-tag GB1 (56 amino acids), including a hexahistidine tag (Huth et al. 1997). To do so, the region encoding the Vmp2 $2_{\text {CTD }}$ was amplified by PCR from genomic DNA of $U$. maydis SG200 and inserted into the $N c o I / X h o I$ sites of the vector pEMGB1. For the overproduction of the full-length constructs, the genes encoding Vmp1 and Vmp2 were amplified from genomic DNA of $U$. maydis SG200 without the signal peptide and subsequently ligated into the pEMstX1 vector using BsaI restriction sites. The protein constructs will be fused to a Mistics-tag (110 amino acids), including a 
83

84

85

86

87

88

89

90

91

92

93

94

95

96

97

98

99

100

101

102

103

104

105

106

107

108

109

110

111

112

113

114

115

116

117

118

119

120

121

122

123

124

125

126

hexahistidine tag (Roosild et al. 2005). In both plasmids, a tobacco etch virus (TEV) cleavage site is located between expression tag and cloned gene.

Strains, growth conditions, and plant infection assays. The Escherichia coli strain Dh5 $\alpha$ (New England Biolabs) was used for cloning purposes. The E. coli strain OverExpress ${ }^{\mathrm{TM}} \mathrm{C} 43$ (DE3) (Sigma-Aldrich) was used to express the full-length constructs of Vmp1 and Vmp2. The E. coli strain BL21 (DE3) (Novagen) was used to express the CTD of Vmp2. E. coli strains were grown under constant shaking in a temperature-controlled incubator. Zea mays cv. Early Golden Bantam (EGB, Urban Farmer, Westfield, IN, USA) was used for infection assays with Ustilago maydis and grown in a temperaturecontrolled greenhouse (light and dark cycles of 14 hours at $28^{\circ} \mathrm{C}$ and 10 hours at $20^{\circ} \mathrm{C}$, respectively). U. maydis strains used in this study are listed in table S3. U. maydis strains were grown in YEPS light medium ( $1 \%(\mathrm{w} / \mathrm{v})$ yeast extract, $0.4 \%(\mathrm{w} / \mathrm{v})$ peptone and $0.4 \%(\mathrm{w} / \mathrm{v})$ sucrose) and subsequently adjusted to an $\mathrm{OD}_{600}$ of 1.0 using sterile double-distilled water. For the infection of maize plants $500 \mu 1$ of $U$. maydis cultures were injected into the stem of 7-day-old maize seedlings using a syringe as described by Kämper and coworkers (Kämper et al. 2006).

Gene knockout in U. maydis. The plasmid pMS73 was digested with Acc65I to integrate the respective sgRNA expression cassette via Gibson Assembly, according to Schuster and coworkers (Schuster et al. 2018). The PCR obtained a double-stranded DNA fragment containing the respective target sequences, scaffold, terminator, and the corresponding overlapping sequences. The fragments were cloned into pMS73 yielding pFA001 and pFA003-pFA007 (Tab. S1). The target sequences (Tab. S2) were designed using the E-CRISP tool (Heigwer, Kerr, and Boutros 2014). The inserts in all plasmids were validated by sequencing.

Generation of $U$. maydis complementation constructs. To generate complementation strains of

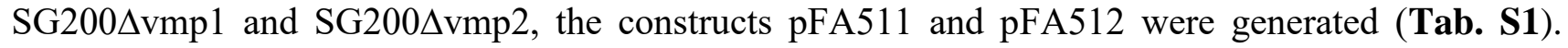
Genomic DNA from U. maydis SG200 containing promoter and open reading frame (ORF) of the respective gene was amplified by PCR using the primers listed in table $\mathbf{S 2}$. The amplified fragments were introduced into the KpnI/NotI sites of plasmid p123 (Aichinger et al. 2003). Prior to transformation, the plasmids were linearized using the restriction enzyme SalI.

Generation of $U$. maydis strains. The genes encoding the six putative transmembrane proteins were disrupted in U. maydis SG200 using the CRISPR-Cas9 approach recently described for genetic manipulation of $U$. maydis (Schuster et al. 2016). A donor DNA was supplied during transformation to delete the respective ORF from the genome without further disruption of neighboring genes (Fig. S2). Isolated $U$. maydis transformants were confirmed for deleting the respective genes by colony PCR using the primers listed in table $\mathbf{S 2}$ and sequencing (Fig. S2). To complement the phenotypes of

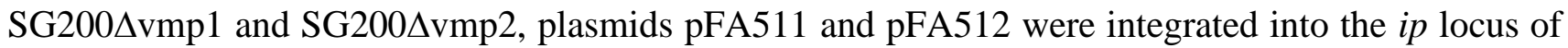
SG200. Isolated $U$. maydis transformants were confirmed by Southern-blot analysis to ensure single integration events in the $i p$ locus (Keon, White, and Hargreaves 1991).

Production and purification of soluble Vmp $2_{C T D}$. The CTD of Vmp2 was produced in E. coli BL21 (DE3) (Novagen). E. coli BL21 (DE3) was transformed with pFA508 to produce Vmp2 $\mathrm{N}$-terminal GB1 tag including a hexahistidine tag. The protein production was performed in autoinductive Luria-Miller broth (Roth) containing $1 \%(\mathrm{w} / \mathrm{v}) \alpha$-lactose (Roth). The cells were grown for $20 \mathrm{~h}$ at $30^{\circ} \mathrm{C}$ and $180 \mathrm{rpm}$. The cultures were harvested by centrifugation $\left(4,000 \mathrm{xg}, 15 \mathrm{~min}, 4^{\circ} \mathrm{C}\right)$, resuspended in HEPES buffer ( $20 \mathrm{mM}$ HEPES, $200 \mathrm{mM} \mathrm{NaCl}, 20 \mathrm{mM} \mathrm{KCl}, 40 \mathrm{mM}$ imidazole, $\mathrm{pH}$ 8.0), and subsequently disrupted using a microfluidizer (M110-L, Microfluidics). The cell debris was removed by centrifugation $\left(50,000 \mathrm{xg}, 20 \mathrm{~min}, 4^{\circ} \mathrm{C}\right)$. The supernatant was loaded onto Ni-NTA FF- 
HisTrap columns (GE Healthcare) for affinity purification via the hexahistidine tag. The columns were washed with HEPES buffer (10x column volume) and eluted with HEPES buffer containing $250 \mathrm{mM}$ imidazole. Prior to size exclusion chromatography (SEC), the GB1-tag was cleaved off by adding 0.8 mg purified TEV protease directly to the eluate and incubating under constant rotation at $20{ }^{\circ} \mathrm{C}$ for 3 hours. Cleaved His-tagged GB1 and remaining TEV protease were removed via a second Ni-NTA purification after buffer exchange to HEPES buffer containing $40 \mathrm{mM}$ imidazole using an Amicon Ultra-10K centrifugal filter (Merck Millipore). The tag-free protein was subjected to SEC using a Superdex S75 Increase 10/300 column equilibrated in HEPES buffer without imidazole and a pH of 7.5. The peak fractions were analyzed using a standard SDS-PAGE protocol, pooled, and concentrated with Amicon Ultra-10K centrifugal filters.

Production and Purification of membrane proteins. The plasmids pFA659 and pFA670 encoding fulllength Vmp2 and Vmp1 were transformed in E. coli OverExpress ${ }^{\text {TM }}$ C43 (DE3) (Sigma-Aldrich). Transformants were grown in Terrific-Broth medium (24 g/l yeast extract, $20 \mathrm{~g} / 1$ tryptone, $4 \mathrm{ml} / \mathrm{l}$ glycerol, buffered with $10 \%$ phosphate buffer $\mathrm{pH} 7.4\left(0.17 \mathrm{M} \mathrm{KH}_{2} \mathrm{PO}_{4}, 0.72 \mathrm{M} \mathrm{K}_{2} \mathrm{HPO}_{4}\right)$ ) under constant shaking at $180 \mathrm{rpm}$ and $37{ }^{\circ} \mathrm{C}$ to an $\mathrm{OD}_{600}$ of $0.5-0.6$. The cultures were then cooled to $20{ }^{\circ} \mathrm{C}$, induced with 0.2 M Isopropyl- $\beta$-D-thiogalactopyranosid (IPTG), and incubated for $20 \mathrm{~h}$ at $20{ }^{\circ} \mathrm{C}$ and $180 \mathrm{rpm}$. The cultures were harvested by centrifugation $\left(4,000 \mathrm{xg}, 15 \mathrm{~min}, 4^{\circ} \mathrm{C}\right)$, resuspended in Trisbuffer (50 mM Tris-Base, $300 \mathrm{mM} \mathrm{NaCl}, 40 \mathrm{mM}$ imidazole, $\mathrm{pH}$ 8.0), and subsequently disrupted using a microfluidizer (M110-L, Microfluidics). The cell debris was removed by centrifugation $(8,000 \mathrm{xg}$, $\left.20 \mathrm{~min}, 4^{\circ} \mathrm{C}\right)$ and the supernatant was centrifuged $\left(115,000 \mathrm{xg}, 1 \mathrm{~h}, 4{ }^{\circ} \mathrm{C}\right)$ using a fixed-angle rotor $(70$ $\mathrm{Ti}$, Beckmann) in an ultracentrifuge (Optima XPN-80, Beckmann). The pellet was resuspended in 10 $\mathrm{ml}$ Tris-Buffer using a Dounce-homogenizer (Carl Roth). The homogenized pellet was mixed with 10 $\mathrm{ml}$ Tris-Buffer containing either $2 \%(\mathrm{w} / \mathrm{v})$ Lauryldimethylamine-N-Oxide (LDAO) or $2 \%(\mathrm{w} / \mathrm{v})$ Dodecyl- $\beta$-D-maltosid (DDM) for Vmp1 and Vmp2, respectively, and incubated for $2.5 \mathrm{~h}$ at $4{ }^{\circ} \mathrm{C}$ under constant rotation. The solubilized membrane was again centrifuged $\left(115,000 \mathrm{xg}, 1 \mathrm{~h}, 4{ }^{\circ} \mathrm{C}\right)$. The supernatant was loaded onto $1 \mathrm{ml}$ Ni-NTA FF-HisTrap columns (GE Healthcare) for affinity purification via the hexahistidine tag. The detergent concentration was lowered to $0.1 \%$ (w/v) during the Ni-NTA purification of both proteins. Prior to SEC, the Mistics-tag was cleaved off by adding 0.8 mg purified TEV directly to the eluate and incubating under constant rotation at $20{ }^{\circ} \mathrm{C}$ for 3 hours. Cleaved His-tagged Mistics and remaining TEV protease were removed via a second Ni-NTA purification after buffer exchange to Tris buffer containing $40 \mathrm{mM}$ imidazole in an Amicon centrifugal filter (Merck Millipore) with adequate cutoff. The protein was subjected to SEC using a Superdex 200 Increase 10/300 column equilibrated in HEPES-buffer $(20 \mathrm{mM} \mathrm{HEPES}, 200 \mathrm{mM} \mathrm{NaCl}, 20 \mathrm{mM} \mathrm{KCl}$, $\mathrm{pH} 7.5$ ) containing either $0.1 \%$ (w/v) LDAO or $0.03 \%$ (w/v) DDM for Vmp1 and Vmp2, respectively. The peak fractions were analyzed using a standard SDS-PAGE protocol, pooled, and concentrated with appropriate Amicon centrifugal filters.

163 Multi-angle light scattering (MALS). Multi-angle light scattering coupled size-exclusion 164 chromatography (SEC-MALS) was performed using an Äkta PURE system (GE Healthcare) with a Superdex 200 Increase 10/300 column attached to a MALS detector 3609 (Postnova Analytics) and a refractive index detector 3150 (Postnova Analytics). The column was equilibrated with $0.2 \mu \mathrm{m}$ filtered HEPES buffer (20 mM HEPES, $200 \mathrm{mM} \mathrm{NaCl}, 20 \mathrm{mM} \mathrm{KCl}, \mathrm{pH} 7.5$ ) containing either $0.1 \%$ (w/v) 168 LDAO or $0.03 \%$ (w/v) DDM for Vmp1 and Vmp2, respectively. For each measurement, $100 \mu 1$ of a $16950 \mu \mathrm{M}$ protein solution was injected.

170 Mass photometry (MP). Mass photometry experiments were performed using a OneMP mass 
$0.9 \mathrm{~ms}$, adjusted to maximize camera counts while avoiding saturation. Microscope slides (70 x 26 $\mathrm{mm}$ ) were cleaned 5 minutes in $50 \%$ (v/v) isopropanol (HPLC grade in Milli-Q $\mathrm{H}_{2} \mathrm{O}$ ) and pure Milli$\mathrm{Q} \mathrm{H}_{2} \mathrm{O}$, followed by drying with a pressurized air stream. Silicon gaskets to hold the sample drops were cleaned in the same manner fixed to clean glass slides immediately prior to measurement. The instrument was calibrated using NativeMark Protein Standard (Thermo Fisher) immediately prior to measurements. Immediately prior to mass photometry measurements, protein stocks were diluted directly in HEPES buffer. Typical working concentrations of Vmp1 and Vmp2 were 25-50 $\mathrm{nM}$ for the actual measurement. Each protein was measured in a new gasket well (i.e., each well was used once). To find focus, $18 \mu \mathrm{l}$ of fresh room temperature buffer was pipetted into a well, the focal position was identified and locked using the autofocus function of the instrument. For each acquisition, $2 \mu \mathrm{L}$ of diluted protein was added to the well and thoroughly mixed. The data were analyzed using the DiscoverMP software.

185 Confocal light microscopy. The proliferation of $U$. maydis in infected maize leaf tissue was visualized 186 by confocal microscopy as described previously (Tanaka et al. 2014). A leaf area of $1 \mathrm{~cm}^{2} l o c a t e d ~ 2$ $\mathrm{cm}$ below the injection site was excised 2 days post-infection (dpi). The leaf samples were destained with ethanol and treated with $10 \%(\mathrm{w} / \mathrm{v})$ potassium hydroxide at $85^{\circ} \mathrm{C}$ for $4 \mathrm{~h}$. The fungal hyphae were stained with Wheat Germ Agglutinin-Alexa Fluor 488 (WGA-AF488, Invitrogen). The plant cell walls were stained with propidium iodide (Sigma-Aldrich) by incubating decolorized samples in staining solution ( $1 \mu \mathrm{g} / \mathrm{ml}$ propidium iodide, $10 \mu \mathrm{g} \mathrm{ml}-1 \mathrm{WGA}-\mathrm{AF} 488)$ and observed with a TCS-SP8 confocal laser-scanning microscope (Leica Microsystems) under the following conditions: WGA-AF488: excitation at $488 \mathrm{~nm}$ and detection at 500-540 nm; propidium iodide: excitation at $561 \mathrm{~nm}$ and detection at 580-660 $\mathrm{nm}$.

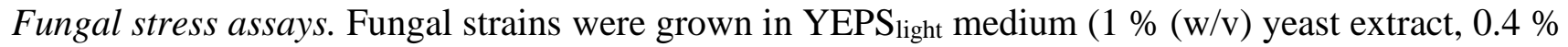
$(\mathrm{w} / \mathrm{v})$ peptone and $0.4 \%(\mathrm{w} / \mathrm{v})$ sucrose) to an $\mathrm{OD}_{600}$ of 1.0. The cells were pelleted and resuspended in sterile double distilled $\mathrm{H}_{2} \mathrm{O}$ to an $\mathrm{OD}_{600} 0.1$. For the induction of filament formation, $10 \mu 1$ of serial dilutions were spotted on potato-dextrose charcoal plates (Holliday 1974). The stress assays were performed on CM plates (Holliday 1974) supplemented with $750 \mu \mathrm{M}$ calcufluor white (SigmaAldrich), $3 \mathrm{mM}$ hydrogen peroxide $\left(\mathrm{H}_{2} \mathrm{O}_{2}\right), 1 \mathrm{M} \mathrm{NaCl}$ or $1 \mathrm{M}$ sorbitol. Images were taken after overnight incubation at $28^{\circ} \mathrm{C}$.

Statistical analysis. Disease symptoms of infected plants were scored at 12 dpi using the previously established scoring scheme by Kämper and colleagues (Kämper et al. 2006). Disease symptoms were quantified based on three biological replicates and are presented as stacked histograms. Significant differences among disease symptoms within individual disease categories were determined by Student's t-test. The raw data of all infection assays and the statistical analysis can be found table S5.

Accession numbers. The genes and encoding protein sequences from $U$. maydis are available at NCBI under the following accession numbers.: vmpl (UMAG_00032), XP_011386009.1; vmp2 (UMAG_01689), XP_011387666.1; UMAG_01713, XP_011387687.1; UMAG_04185, XP_011390672.1; UMAG_10491, XP_011390314.1; UMAG_03474, XP_011389930.1.

\section{Results}

212 Identification of membrane proteins critical for pathogenic development of U. maydis.

213 To identify membrane proteins that show an increase in transcript abundance during infection stages

214 associated with biotrophic development of Ustilago maydis, we analyzed the transcriptomic data 215 obtained by Lanver and coworkers (Lanver et al. 2018). Highly upregulated protein-encoding genes 
were then examined for the presence of potential transmembrane helices (TMs) using the Consensus Constrained TOPology prediction web server CCTOP (Fig. S1) (Dobson, Reményi, and Tusnády 2015). By this approach, we could identify six genes strongly elevated during infection and their respective proteins containing at least one predicted TM. They show their strongest expression two to four days post-infection while not induced in axenic culture under non-infective conditions (Fig. 1A). These proteins are UMAG_00032, UMAG_01689, UMAG_01713, UMAG_03474, UMAG_04185, and UMAG_10491.

To evaluate these protein's impact on virulence, we deleted their respective genes in the solopathogenic U. maydis strain SG200 (Kämper et al. 2006). The gene deletion was performed using a CRISPR-Cas9based approach as described by Schuster and coworkers (Schuster et al. 2016). A donor DNA was supplied to delete the respective open reading frames (ORF's) from the genome while keeping the surrounding genetic environment intact (Fig. S2). The deletion of four genes resulted in a wildtypelike behavior during maize infection experiments (UMAG_01713,UMAG_03474,UMAG_04185, and $\left.U M A G_{-} 10491\right)$, the two other genes (UMAG_00032 and $U M A G_{-}$01689) lead to attenuation in virulence (Fig. 1B). To investigate whether the differences in phenotypical symptoms between the deletion strains of $U M A G_{-} 00032, U M A G_{-} 01689$, and SG200 are significant, we scored the disease symptoms of each infected plant using a previously established scoring scheme (Kämper et al. 2006). For the significance-analysis, we performed a two-sided Student's t-test. Our analysis for each category confirmed that the differences are significant, with p-values below 0.05 for several categories (Tab. S5).

Our results reveal two TM proteins that strongly impact the virulence of $U$. maydis during maize infection. Therefore, we named both genes vmp1 (UMAG_00032) and vmp2 (UMAG_01689) for virulence-associated membrane protein 1 and 2.

\section{Vmp1 and vmp2 are conserved among related smut species}

Vmpl encodes a protein of 142 amino acids (aa), whereas vmp2 encodes a 335 aa long protein. Both proteins contain an N-terminal signal peptide (SP) of 25 aa, as predicted by SignalP-5.0 (Almagro Armenteros et al. 2019). Our in silico analyses indicate that both proteins harbor one TM helix spanning the residues 60 to 77 in Vmp1 and residues 100 to 115 in Vmp2 (Fig. S1). The N-terminal domain (NTD) of both proteins is predicted to be extracellular (Fig S1).

In a next step, we analyzed the genetic context of both proteins in $U$. maydis and compared it to related smut fungi. Using the Basic Local Alignment Search Tool (BLAST) we identified Vmp1 orthologs in the genomes of Pseudozyma hubeiensis SY62, Kalmanozyma brasiliensis GHG001, Sporisorium reilianum SRZ2, Ustilago trichophora, Sporisorium scitamineum, Moesziomyces antarcticus, Moesziomyces aphidis DSM 70725, and Testicularia cyperi with identities ranging from $58 \%$ to $34 \%$ (determined by CLUSTAL2.1) (Fig. S3A). However, it was absent in Ustilago hordei or Ustilago bromivora with the genetic context being similar to U. maydis (Fig. 2A). A protein related to Vmp1 was also identified in the genome of $T$. cyperi a pathogen of Rhynchospora spp. (Kijpornyongpan et al. 2018). The genetic context showed differences to the closely related species due to the ancestral nature of $T$. cyperi (Fig. 2A).

The neighboring genes encode a proline dehydrogenase (UMAG_00030), a TM protein of unknown function (UMAG_00031), a $\mathrm{Zn}_{2}$-C6 fungal-type transcription factor (UMAG_10009), and a putative MFS transporter (UMAG_00034) (Fig. 2A). These genes are also induced during axenic growth and might thus not be directly related to virulence. However, UMAG_00034 shows elevated transcript 
levels between $24 \mathrm{~h}$ and $48 \mathrm{~h}$ post-infection while not induced during axenic growth (Lanver et al. 2018).

We also identified orthologs of Vmp2 in a variety of related smut fungi (Fig. S3B). Namely, $P$. hubeiensis SY62, U. bromivora, Sporisorium graminicola, S. reilianum SRZ2, U. hordei, K. brasiliensis GHG001, U. trichophora, M. antarcticus, S. scitamineum, and T. cyperi. Here, the sequence identities ranged from $43 \%$ to $36 \%$ (Fig. S3B). Notably, Vmp2 is highly conserved from amino acid 82 to 195 (within the Vmp2 sequence from $U$. maydis), while the C-terminus shows a higher degree of deviation in the investigated orthologs (Fig. S3B). In Ustilaginaceae, the loci of $v m p 2$ are similarly to vmpl highly syntenic although the intergenic region towards UMAG_01690 and its orthologs shows some length differences (Fig. 2B). The neigbhouring genes include an OBG-type Gdomain-containing protein (UMAG_01687), a putative nuclear transport factor (UMAG_01688), a secreted effector protein of unknown function $\left(U M A G_{-} 01690\right)$ and a DNA helicase (UMAG_01691) (Fig. 2B).

\section{Vmpl hinders fungal infection after penetration of the plant epidermis}

273 The vmpl deletion strain showed the strongest reduction in virulence with tumor formation being of the infection site, a universal sign of infections and thus the presence of infectious hyphae (Tanaka et al. 2014). The deletion strain SG200 $\Delta \mathrm{vmp} 1$ was complemented by integrating a single copy of $\mathrm{vmpl}$

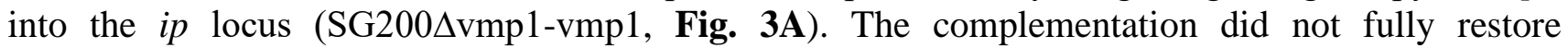
SG200Avmp1, leading mainly to the formation of smaller tumors and larger ones only to a lesser extent (Fig. 3A, B). Thus, we wanted to know whether SG200 $\Delta$ vmp1 remains able to grow inside vascular bundles and elicits a plant defense response or whether fungal growth is arrested after penetration of the epidermal layer.

To detect differences in host colonization, we visualized fungal hyphae by staining with WGA-AF488

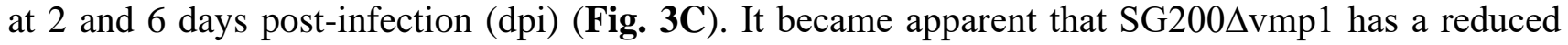
number of fungal hyphae on the plant leaf surface combined with less proliferation (Fig. 3C). However, hyphae could still penetrate the epidermal layer and grow inside the vascular bundles (Fig. 3C). Fungal growth was seemingly arrested at this stage as the amount of fungal material inside the plant leaves was not drastically increased at 6 dpi (Fig. 3C). To rule out that the reduced virulence was due to reduced growth and stress sensitivity, we grew SG200دvmp1 in the presence of $\mathrm{NaCl}$, sorbitol, calcofluor white, and $\mathrm{H}_{2} \mathrm{O}_{2}$. However, mutant strains were indistinguishable from SG200 (Fig. S4).

In conclusion, we show that the TM protein encoded by vmpl is essential for full virulence and might be important for establishing the biotrophic interface. It is conserved among related smut fungi (Fig. S3A) indicating that its function might also be conserved among these relatives.

\section{Vmp2 leads to reduced tumor formation}

The deletion of $v m p 2$ led to a strong reduction in virulence of $U$. maydis, with solely small tumors being formed (Fig. 4A). We complemented SG200 $\Delta \mathrm{vmp} 2$ by integrating a single copy of $v m p 2$ into the ip locus (SG200 $\Delta \mathrm{vmp} 2-\mathrm{vmp} 2$, Fig. 4A, B). This complementation could fully restore the phenotype of SG200 $\Delta \mathrm{vmp} 2$. To rule out that the deletion of vmp2 leads to altered growth of $U$. maydis under stress conditions, we grew SG200 $\Delta \mathrm{vmp} 2$ in the presence of $\mathrm{NaCl}$, sorbitol, calcofluor white and $\mathrm{H}_{2} \mathrm{O}_{2}$ and did not detect differences from SG200 (Fig. S4). 
300

301

302

303

304

305

306

307

308

309

310

311

312

313

314

315

316

317

318

319

320

321

322

323

324

325

326

327

328

329

330

331

332

333

334

335

336

337

338

339

340

341

342

343

In the next step, we aimed to understand how deleting the two predicted soluble domains would impact the function of Vmp2 in vivo (Fig. S1). We generated two constructs deleting either the predicted extracellular NTD or the cytosolic CTD and transformed U. maydis SG200 to perform infection assays

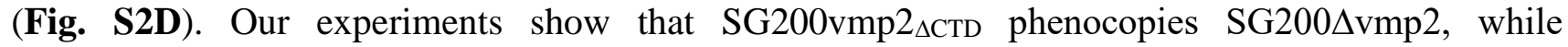
SG200vmp $2_{\triangle \mathrm{NTD}}$ is less attenuated in virulence (Fig. 4A, B).

Taken together, we can show that $v m p 2$ is an essential player for the infection process in $U$. maydis and potentially related organisms. Additionally, our infection experiments indicate that the CTD of Vmp2 is important for full virulence.

\section{Vmpl shows concentration-dependent oligomerization}

To allow for a biochemical investigation of Vmp1, we cloned the open reading frame without the signal peptide (residues 1-20) for heterologous protein production in E. coli (see materials \& methods). First expression and solubility tests did not allow to purify the full-length protein in amounts sufficient for biochemical analysis. Thus, we generated a construct that includes an N-terminal Mistics-tag (MstX) separated by a TEV protease cleavage site. This 110 amino acid long protein tag forms four transmembrane helices and inserts autonomously in the membrane. It has been used to improve the expression of membrane proteins in several cases (Roosild et al. 2005). In our case, the production of MstX-Vmp1 was drastically enhanced compared to protein production without the fusion-tag. Attempts to solubilize MstX-Vmp1 from the membrane fraction using Dodecyl- $\beta$-D-maltosid (DDM) failed and thus we tested a variety of commercially available detergents. Solubilization was only achieved employing Lauryldimethylamine-N-Oxide (LDAO). Notably, all attempts to cleave the MstX tag via TEV cleavage only resulted in inefficient and partial cleavage. It is likely that the spacing between the membrane-embedded MstX and the membrane spanning helix within Vmp1 (residues 60 - 77) might not allow for a proper TEV recognition and cleavage. Consequently, we used the fulllength fusion protein for biochemical analysis.

Purified MstX-Vmp1 was subjected to size-exclusion chromatography coupled multi-angle light scattering (SEC-MALS) using a Superdex 200 Increase 3.2/300 column equilibrated with SEC buffer including $0.1 \%$ LDAO (see materials \& methods). The protein eluted in a single peak at $1.62 \mathrm{ml}$ corresponding to $90 \mathrm{kDa}$ according to the calibration calculation for this column (Fig. 5A). Our analysis with MALS and refractive index resulted in a mass of $113 \pm 17 \mathrm{kDa}$ and thus yielded a slightly higher molecular weight (Fig. 5A). The calculated mass of the MstX-Vmp1 fusion protein is around $31 \mathrm{kDa}$. MALS allowed us to clearly distinguish between empty micelles and the membrane proteindetergent complexes. Notably, the molecular weight of free LDAO micelles was found to be $40 \pm 5$ $\mathrm{kDa}$ in our experiments and thus a bit larger than 16-20 kDa reported in literature (Timmins et al. 1988). As membrane proteins are likely not embedded into detergent micelles but rather form membrane protein-detergent complexes (Chaptal et al. 2017), our results indicate that two or three Vmp1 molecules would be encaged by LDAO detergent molecules.

To achieve a better resolution of Vmp1 oligomerization, we employed mass photometry, a method that became recently available and allows rapid and reliable determination of the dynamic molecular weight of macromolecules in solution (Olerinyova et al. 2021; F et al. 2020). We firstly used a final concentration of $25 \mathrm{nM}$ MstX-Vmp1 for mass photometric analysis which was achieved by rapid 1:10 dilution of a $250 \mathrm{nM}$ solution into SEC buffer without detergent. Approximately $60 \%$ of MstX-Vmp1 had a measured mass of $42 \mathrm{kDa}$ (Fig. 5B) suggesting a monomer of MstX-Vmp1 and 50 LDAO detergent molecules $(11 \mathrm{kDA})$. A subfraction higher molecular weight assemblies was also visible, however gaussian fitting was not possible at this concentration. When using $50 \mathrm{nM}$ of MstX-Vmp1, a 
second gaussain could be fitted additionally to the $60 \%$ of molecules with a mass of $42 \mathrm{kDa}$ indicating the presence of a $118 \mathrm{kDa}$ species containing $20 \%$ of all molecules (Fig. 5C). To rule out that no empty LDAO micelles were detected, we subjected a buffer containing no protein and only LDAO at the working concentration of $0.01 \%$ to mass photometry. However, no events were detectable suggesting that micelles are not formed at this detergent concentration.

Taken together, we conclude that Vmp1 mainly occurs as a monomer but forms higher oligomeric species at higher concentrations.

\section{Vmp2 is a dimeric membrane protein}

352

353

354

355

356

357

In a next step, we aimed to investigate Vmp2 after heterologous protein production in E. coli. Similar to Vmp1, the expression of full-length Vmp2 was insufficient for biochemical analyses and only the fusion of an N-terminal Mistics-tag allowed to obtain adequate amounts of membrane-bound protein. Vmp2 could be solubilized with DDM and was purified using a Superose 6 Increase 10/300 column (GE Healthcare) equilibrated with SEC buffer and $0.03 \%$ DDM (see materials \& methods). The protein eluted at $17.22 \mathrm{ml}$ corresponding to a molecular weight of approx. $83 \mathrm{kDa}$ (Fig. 6A).

We again employed mass photometry to accurately determine the molecular weight of Vmp2 and investigate whether different oligomeric species might be visible even at nanomolar concentrations. However, using DDM as detergent, $0.03 \%$ (w/v), which is aquivalent to $600 \mu \mathrm{M}$ and thus generated a strong detergent background that did not allow us to distinguish between empty micelles and Vmp2. Thus, we investigated whether Vmp2 would be stable in LDAO or lauryl maltose neopentyl glycol (LMNG), a detergent that contains two DDM moieties and has a very low CMC at $10 \mu \mathrm{M}$ which is perfectly suited for mass photometry. We thus solubilized Vmp2 using DDM and exchanged the detergent during Ni-ion affinity chromatography and applied the protein to a Superose 6 Increase $10 / 300$ column equilibrated in $0.1 \%$ LDAO or $0.001 \%$ LMNG, respectively.

Firstly, Vmp2 purified in the presence of $0.1 \%$ LDAO was measured (Fig. 6B). To remove excess detergent micelles during mass photometry, a stock solution at $1 \mu \mathrm{M}$ of $\mathrm{Vmp} 2$ was rapidly diluted 1:10 in SEC buffer without detergent. A Gaussian fit of the peak fraction contained $92 \%$ of all measured molecules at a MW of $81 \mathrm{kDa}$. In a second approach, we used Vmp2 solubilized in $0.001 \%$ LMNG and again rapidly diluted it 1:10 in SEC buffer containing no detergent. Here, we could fit $84 \%$ of all counts resulting in a MW of approximately $94 \mathrm{kDa}$ (Fig. 6C). The mass differences between the LDAO and LMNG solubilized Vmp2 likely is a result from the different protein-detergent complex sizes formed by the two detergent molecules. As Vmp2 has a theoretical molecular weight of $32 \mathrm{kDa}$, the $81 \mathrm{kDa}$ would correspond to a dimer of Vmp2 and 75 LDAO (17 kDa) detergent molecules, while the $94 \mathrm{kDa}$ suggest a Vmp2 dimer and $30 \mathrm{LMNG}$ (30 kDa) detergent molecules.

In summary, our mass photometry results are in agreement with the MW calculated from size exclusion chromatography and indicate the presence of a Vmp2 dimer.

\section{The CTD of Vmp2 is largely unstructured and does not contribute to dimerization}

Next, we investigated the predicted cytosolic CTD of Vmp2. We subjected purified Vmp2 Superdex 75 Increase 10/300 column. The protein eluted at $9.28 \mathrm{ml}$ which corresponds to a molecular weight of $45 \mathrm{kDa}$ (Fig. 6D). However, multi-angle light scattering coupled SEC (SEC-MALS) unambiguously revealed a MW of $25 \pm 1,5 \mathrm{kDa}$ of $\mathrm{Vmp} 2_{\mathrm{CTD}}$ (Fig. 5D). Our secondary structure and disorder prediction through PSIPRED indicated that residues 200 to 335 are potentially disordered (Fig. S5). As disordered or non-globular proteins show a different migration behavior than the SEC- 
standard, this would explain the discrepancy between SEC and MALS MW calculation. In conclusion, we can show that Vmp2 is dimeric membrane protein with a CTD that is largely unstructured and does not contribute to dimerization.

\section{Discussion}

In this study, we have identified six genes that are strongly induced between 0.5 and 2 days postinfection (dpi) and remain upregulated until 12 dpi (Fig. 1A), while not being expressed in axenic culture. This expression pattern correlates with establishing and maintaining biotrophy, a critical feature of pathogenic development in smut fungi (Lanver et al. 2018). Our in silico analysis suggested that all of them harbor at least one transmembrane spanning helix, rendering them interesting targets as proteins associated with virulence in smut fungi are predominantly soluble effectors (Lanver et al. 2017). The deletion of two of them, subsequently named Vmp1 and Vmp2 (virulence associated membrane protein), resulted in a strong attenuation of virulence during maize infection, while growth of the deletion strains was neither affected in axenic liquid culture nor in the presence of various stress causing agents (Fig. S4). We can thus conclude that both Vmp1 and Vmp2 are important during pathogenic but not axenic growth of $U$. maydis. Attempts to reveal a potential function of these TM proteins by the prediction of functional domains yielded no results for Vmp1 and Vmp2 using the DomPred server embedded in the PSIPRED algorithm (Buchan and Jones 2019).

To shed light on the function of Vmp1, we inspected the deletion strains in more detail. Deletion of Vmp1 led to a strong attenuation of fungal growth that was arrested after epidermal penetration (Fig. 2C) although some hyphae were still visible growing inside vascular bundles. Notably, tumor formation on maize leaves inoculated with vmp1 mutant strains was not observed in infection experiments. Vmp1 thus plays a critical role during the early infection stages. Notably, vmp1 mutant strains still elicited a plant defense response as anthocyanin production could still be observed on infected plant leaves.

Our biochemical analysis suggested that Vmp1 predominantly occurs as a monomer (Fig. 5B) as the cellular concentrations of Vmp1 will most likely be low. This is further supported by the gene expression data as vmpl shows the lowest expression of all six transmembrane protein encoding genes investigated (Fig. 1A). During investigation of the genomic context of $v m p 1$, it became apparent that the gene UMAG_00031 is found in the same orientation upstream of vmp1 in several related species. A recent study demonstrated that $U M A G \_00031$ encodes a putative transmembrane protein potentially involved in $\mathrm{pH}$ regulation (Cervantes-Montelongo et al. 2020). In contrast to SG2004vmp1, UMAG_00031 mutant strains showed reduced growth under pH stresses as well as in the presence of sorbitol and $\mathrm{NaCl}$ (Cervantes-Montelongo et al. 2020). The study suggested UMAG_00031 to be a member of the Pal/Rim pathway in $U$. maydis, a widely conserved signaling pathway involved in $\mathrm{pH}$ adaptation (Selvig and Alspaugh 2011; Fonseca-García, León-Ramírez, and Ruiz-Herrera 2012). However, our data indicate that Vmp1 is most likely not directly involved in $\mathrm{pH}$ adaptation or regulation. It might still play an accessory role in these processes serving e.g. as adaptor protein. Here, future research might identify a connection towards $\mathrm{pH}$ related regulation to during plant infection. 
Vmp2 (UMAG_01689) has already been identified to contribute to virulence in $U$. maydis (Uhse et al. 2018). In their study, the authors also showed that the fungal biomass is strongly reduced in infected plant leaves. However, as the knockout was only delivered as a proof-of-concept of their method to identify genes essential for virulence, no further information on Vmp2 was provided. Our data confirm the phenotype observed by Uhse and coworkers (Fig. 4A). Furthermore, we can show that Vmp2 has a short N-terminal (NTD) and a long C-terminal domain (CTD). While deletion of the CTD phenocopies SG200Dvmp2, strains deleted for the NTD cause slightly more severe symptoms on infected plants. This suggests that the CTD is indispensable for virulence. Sequence alignments to homologs from other smut fungi show that the C-termini is highly variable, while the region surrounding the membrane spanning helix is conserved (Fig. S3). Our analysis by SEC-coupled MALS confirmed that the CTD is largely unstructured. Proteins containing unstructured regions have been characterized in the context of many scenarios and can make up substantial amounts of the total protein content (Van Der Lee et al. 2014). A possible scenario is that the unstructured region of Vmp1 becomes ordered in the context of an interaction partner. Here, the sequence variability in related organisms suggests that this interface is species-specific. Another possible explanation might be that the unstructured domain is involved in membrane shaping or impacts the local membrane heterogeneity (Fakhree, Blum, and Claessens 2019). A thorough investigation of the interactome of Vmp2 in planta might deliver an explanation for the role of CTD of Vmp2 during maize infection of $U$. maydis.

In conclusion, we here present two membrane proteins that act as virulence factors during maize colonization of $U$. maydis. While we deliver an initial characterization of the two proteins expanding the current knowledge on virulence associated membrane proteins of smut fungi, future research needs to address their precise functions.

\section{Conflict of Interest}

449 The authors declare that the research was conducted in the absence of any commercial or financial 450 relationships that could be construed as a potential conflict of interest.

\section{Author Contributions}

452 F.A. conceived of the project and designed the study. F.A. and P.W. performed experiments, 453 analysed data and wrote the paper.

\section{$454 \quad 7 \quad$ Funding}

455 F. A. thanks the Peter und Traudl Engelhorn foundation for financial support.

\section{Acknowledgments}

457 We thank Gert Bange for financial support and helpful discussion on the manuscript and Regine

458 Kahmann for her continuous support throughout the work on this manuscript. We are grateful to 459 Georg Hochberg for access to the Refeyn One mass photometer and to Pietro Giammarinaro for 460 subsequent assistance with data collection.

4619 Contribution to the Field Statement 
462

463

464

465

466

467

468

469

470

471

472

473

474

475

476

477

478

479

480

481

482

483

484

485

486

487

488

489

490

491

492

493

494

495

496

497

498

499

500

501

502

503

504

505

Fungal phytopathogens are an increasing threat to important crops such as wheat, sugar cane, and maize. The smut fungi Ustilago maydis specifically infects the sweet corn Zea mays and leads to annual crop losses of up to $20 \%$. The pathogen needs to establish a biotrophic interaction with its host in order to gain access to valuable resources for life cycle completion. Maintaining this tight interaction, without triggering any immune responses of the host is mainly accomplished by the secretion of a variety of effector proteins in the apoplastic space between host and parasite. Many of those soluble effector proteins have recently been described to be involved in the attenuation of defense mechanisms and the manipulation of host cell metabolism. However, we still don't fully understand the underlying principles of important processes such as cellular host recognition and attachment, the endosomal transport of proteins to the apoplastic space and host cells, or the uptake of signals and nutrients. Membrane-bound proteins with elevated expression during the pathogenic development of $U$. maydis are highly likely to be involved in these processes and should therefore attract more attention in this research field. By delivering an initial characterization of two membrane proteins required for virulence, we highlight the importance of membrane proteins for understanding the infection process of $U$. maydis.

\section{References}

Aichinger, C., K. Hansson, H. Eichhorn, F. Lessing, G. Mannhaupt, W. Mewes, and R. Kahmann. 2003. "Identification of Plant-Regulated Genes in Ustilago Maydis by Enhancer-Trapping Mutagenesis." Molecular Genetics and Genomics 270 (4): 303-14. https://doi.org/10.1007/s00438-003-0926-z.

Almagro Armenteros, José Juan, Konstantinos D. Tsirigos, Casper Kaae Sønderby, Thomas Nordahl Petersen, Ole Winther, Søren Brunak, Gunnar von Heijne, and Henrik Nielsen. 2019. "SignalP 5.0 Improves Signal Peptide Predictions Using Deep Neural Networks." Nature Biotechnology 37 (4): 420-23. https://doi.org/10.1038/s41587-019-0036-z.

Buchan, Daniel W.A., and David T. Jones. 2019. "The PSIPRED Protein Analysis Workbench: 20 Years On.” Nucleic Acids Research 47 (W1): W402-7. https://doi.org/10.1093/nar/gkz297.

Cervantes-Montelongo, Juan Antonio, Guillermo Antonio Silva-Martínez, Raquel Pliego-Arreaga, Lorenzo Guevara-Olvera, and José Ruiz-Herrera. 2020. "The UMAG_00031 Gene from Ustilago Maydis Encodes a Putative Membrane Protein Involved in PH Control and Morphogenesis." Archives of Microbiology 202 (8): 2221-32. https://doi.org/10.1007/s00203020-01936-6.

Chaptal, Vincent, Frédéric Delolme, Arnaud Kilburg, Sandrine Magnard, Cédric Montigny, Martin Picard, Charlène Prier, et al. 2017. "Quantification of Detergents Complexed with Membrane Proteins." Scientific Reports 7: 1-12. https://doi.org/10.1038/srep41751.

Dean, Ralph, Jan A L Van Kan, Zacharias A Pretorius, Kim E Hammond-Kosack, Antonio Di Pietro, Pietro D Spanu, Jason J Rudd, et al. 2012. "The Top 10 Fungal Pathogens in Molecular Plant Pathology.” Molecular Plant Pathology 13 (4): 414-30. https://doi.org/10.1111/j.13643703.2011.00783.x.

Dobson, László, István Reményi, and Gábor E. Tusnády. 2015. "CCTOP: A Consensus Constrained TOPology Prediction Web Server.” Nucleic Acids Research 43 (W1): W408-12. https://doi.org/10.1093/nar/gkv451.

Doehlemann, Gunther, Stefanie Reissmann, Daniela Aßmann, Martin Fleckenstein, and Regine Kahmann. 2011. "Two Linked Genes Encoding a Secreted Effector and a Membrane Protein Are Essential for Ustilago Maydis-Induced Tumour Formation." Molecular Microbiology 81 
F, Soltermann, Foley EDB, Pagnoni V, Galpin M, Benesch JLP, Kukura P, and Struwe WB. 2020. "Quantifying Protein-Protein Interactions by Molecular Counting With Mass Photometry." Angewandte Chemie (International Ed. in English). https://doi.org/10.1002/ANIE.202001578.

Fakhree, Mohammad A.A., Christian Blum, and Mireille M.A.E. Claessens. 2019. "Shaping Membranes with Disordered Proteins." Archives of Biochemistry and Biophysics 677 (July): 108163. https://doi.org/10.1016/j.abb.2019.108163.

Fisher, Matthew C., Daniel. A. Henk, Cheryl J. Briggs, John S. Brownstein, Lawrence C. Madoff, Sarah L. McCraw, and Sarah J. Gurr. 2012. "Emerging Fungal Threats to Animal, Plant and Ecosystem Health.” Nature 484 (7393): 186-94. https://doi.org/10.1038/nature10947.

Fonseca-García, Citlali, Claudia G. León-Ramírez, and José Ruiz-Herrera. 2012. "The Regulation of Different Metabolic Pathways through the Pal/Rim Pathway in Ustilago Maydis." FEMS Yeast Research 12 (5): 547-56. https://doi.org/10.1111/j.1567-1364.2012.00805.x.

Giraldo, Martha C., and Barbara Valent. 2013. "Filamentous Plant Pathogen Effectors in Action." Nature Reviews Microbiology 11 (11): 800-814. https://doi.org/10.1038/nrmicro3119.

Heigwer, Florian, Grainne Kerr, and Michael Boutros. 2014. "E-CRISP: Fast CRISPR Target Site Identification.” Nature Methods. Nat Methods. https://doi.org/10.1038/nmeth.2812.

Holliday, Robin. 1974. "Ustilago Maydis.” In Bacteria, Bacteriophages, and Fungi, 575-95. Springer US. https://doi.org/10.1007/978-1-4899-1710-2_31.

Huth, Jeffrey R., Carole A. Bewley, Belinda M. Jackson, Alan G. Hinnebusch, G. Marius Clore, and Angela M. Gronenborn. 1997. "Design of an Expression System for Detecting Folded Protein Domains and Mapping Macromolecular Interactions by NMR.” Protein Science 6 (11): 235964. https://doi.org/10.1002/pro.5560061109.

Kämper, Jörg, Regine Kahmann, Michael Bölker, Li-Jun Ma, Thomas Brefort, Barry J Saville, Flora Banuett, et al. 2006. "Insights from the Genome of the Biotrophic Fungal Plant Pathogen Ustilago Maydis.” Nature 444 (7115): 97-101. https://doi.org/10.1038/nature05248.

Keon, John P.R., Gordon A. White, and John A. Hargreaves. 1991. "Isolation, Characterization and Sequence of a Gene Conferring Resistance to the Systemic Fungicide Carboxin from the Maize Smut Pathogen, Ustilago Maydis." Current Genetics 19 (6): 475-81. https://doi.org/10.1007/BF00312739.

Kijpornyongpan, Teeratas, Stephen J Mondo, Kerrie Barry, Laura Sandor, Juna Lee, Anna Lipzen, Jasmyn Pangilinan, et al. 2018. "Broad Genomic Sampling Reveals a Smut Pathogenic Ancestry of the Fungal Clade Ustilaginomycotina." Molecular Biology and Evolution 35 (8): 1840-54. https://doi.org/10.1093/molbev/msy072.

Lanver, Daniel, André N. Müller, Petra Happel, Gabriel Schweizer, Fabian B. Haas, Marek Franitza, Clément Pellegrin, et al. 2018. "The Biotrophic Development of Ustilago Maydis Studied by RNA-Seq Analysis.” The Plant Cell 30 (2): 300-323. https://doi.org/10.1105/tpc.17.00764.

Lanver, Daniel, Marie Tollot, Gabriel Schweizer, Libera Lo Presti, Stefanie Reissmann, Lay-Sun Ma, Mariana Schuster, et al. 2017. "Ustilago Maydis Effectors and Their Impact on Virulence." Nature Reviews Microbiology 15 (7): 409-21. https://doi.org/10.1038/nrmicro.2017.33.

Lee, Robin Van Der, Marija Buljan, Benjamin Lang, Robert J. Weatheritt, Gary W. Daughdrill, A. Keith Dunker, Monika Fuxreiter, et al. 2014. "Classification of Intrinsically Disordered Regions and Proteins." Chemical Reviews 114 (13): 6589-6631. https://doi.org/10.1021/cr400525m. 
Lemoine, Remi, Sylvain La Camera, Rossitza Atanassova, Fabienne Dédaldéchamp, Thierry Allario, Nathalie Pourtau, Jean-Louis Bonnemain, et al. 2013. "Source-to-Sink Transport of Sugar and Regulation by Environmental Factors." Frontiers in Plant Science 4: 272. https://doi.org/10.3389/fpls.2013.00272.

Matei, Alexandra, Corinna Ernst, Markus Günl, Björn Thiele, Janine Altmüller, Virginia Walbot, Björn Usadel, and Gunther Doehlemann. 2018. "How to Make a Tumour: Cell Type Specific Dissection of Ustilago Maydis-Induced Tumour Development in Maize Leaves.” The New Phytologist 217 (4): 1681-95. https://doi.org/10.1111/nph.14960.

Morkunas, Iwona, and Lech Ratajczak. 2014. "The Role of Sugar Signaling in Plant Defense Responses against Fungal Pathogens.” Acta Physiologiae Plantarum 36 (7): 1607-19. https://doi.org/10.1007/s11738-014-1559-z.

Mueller, Olaf, Regine Kahmann, Guillermo Aguilar, Blanca Trejo-Aguilar, Andy Wu, and Ronald P de Vries. 2008. "The Secretome of the Maize Pathogen Ustilago Maydis." Fungal Genetics and Biology: FG \& B 45 Suppl 1 (August): S63-70. https://doi.org/10.1016/j.fgb.2008.03.012.

Olerinyova, Anna, Adar Sonn-Segev, Joseph Gault, Cédric Eichmann, Johannes Schimpf, Adrian H. Kopf, Lucas S.P. Rudden, et al. 2021. "Mass Photometry of Membrane Proteins." Chem 7 (1): 224-36. https://doi.org/10.1016/j.chempr.2020.11.011.

Roosild, Tarmo P., Jason Greenwald, Mark Vega, Samantha Castronovo, Roland Riek, and Senyon Choe. 2005. "NMR Structure of Mistic, a Membrane-Integrating Protein for Membrane Protein Expression.” Science 307 (5713): 1317-21. https://doi.org/10.1126/science.1106392.

Sambrook J, Fritsch EF, Maniatis T. 1989. “Molecular Cloning: A Laboratory Manual.” Cold Spring Harbor Laboratory.

Schuler, David, Ramon Wahl, Kathrin Wippel, Miroslav Vranes, Martin Münsterkötter, Norbert Sauer, and Jörg Kämper. 2015. "Hxt1, a Monosaccharide Transporter and Sensor Required for Virulence of the Maize Pathogen Ustilago Maydis." The New Phytologist 206 (3): 1086-1100. https://doi.org/10.1111/nph.13314.

Schuster, Mariana, Gabriel Schweizer, Stefanie Reissmann, and Regine Kahmann. 2016. “Genome Editing in Ustilago Maydis Using the CRISPR-Cas System." Fungal Genetics and Biology : FG \& B 89 (April): 3-9. https://doi.org/10.1016/j.fgb.2015.09.001.

Schuster, Mariana, Christine Trippel, Petra Happel, Daniel Lanver, Stefanie Reißmann, and Regine Kahmann. 2018. "Single and Multiplexed Gene Editing in Ustilago Maydis Using CRISPRCas9." Bio-Protocol 8 (14): 1-15. https://doi.org/10.21769/bioprotoc.2928.

Selvig, Kyla, and J. Andrew Alspaugh. 2011. "PH Response Pathways in Fungi: Adapting to HostDerived and Environmental Signals." Mycobiology. Taylor \& Francis. https://doi.org/10.5941/MYCO.2011.39.4.249.

Sosso, Davide, Karina van der Linde, Margaret Bezrutczyk, David Schuler, Karina Schneider, Jörg Kämper, and Virginia Walbot. 2019. "Sugar Partitioning between Ustilago Maydis and Its Host Zea Mays L during Infection.” Plant Physiology 179 (4): 1373-85. https://doi.org/10.1104/pp.18.01435.

Tanaka, Shigeyuki, Thomas Brefort, Nina Neidig, Armin Djamei, Jörg Kahnt, Wilfred Vermerris, Stefanie Koenig, Kirstin Feussner, Ivo Feussner, and Regine Kahmann. 2014. “A Secreted Ustilago Maydis Effector Promotes Virulence by Targeting Anthocyanin Biosynthesis in Maize." ELife 3 (January). https://doi.org/10.7554/eLife.01355. 
592

593

594

595

596

597

598

599

600

601

602

603

604

605

606
Timmins, P. A., M. Leonhard, H. U. Weltzien, T. Wacker, and W. Welte. 1988. “A Physical Characterization of Some Detergents of Potential Use for Membrane Protein Crystallization." FEBS Letters 238 (2): 361-68. https://doi.org/10.1016/0014-5793(88)80513-1.

Uhse, Simon, Florian G. Pflug, Alexandra Stirnberg, Klaus Ehrlinger, Arndt von Haeseler, and Armin Djamei. 2018. "In Vivo Insertion Pool Sequencing Identifies Virulence Factors in a Complex Fungal-Host Interaction." Edited by Joseph Heitman. PLOS Biology 16 (4): e2005129. https://doi.org/10.1371/journal.pbio.2005129.

Wahl, Ramon, Kathrin Wippel, Sarah Goos, Jörg Kämper, and Norbert Sauer. 2010. “A Novel HighAffinity Sucrose Transporter Is Required for Virulence of the Plant Pathogen Ustilago Maydis." PLoS Biology 8 (2): e1000303. https://doi.org/10.1371/journal.pbio.1000303.

Zuo, Weiliang, Bilal Ökmen, Jasper R.L. Depotter, Malaika K. Ebert, Amey Redkar, Johana Misas Villamil, and Gunther Doehlemann. 2019. "Molecular Interactions Between Smut Fungi and Their Host Plants." Annual Review of Phytopathology 57 (1): annurev-phyto-082718-100139. https://doi.org/10.1146/annurev-phyto-082718-100139. 
A
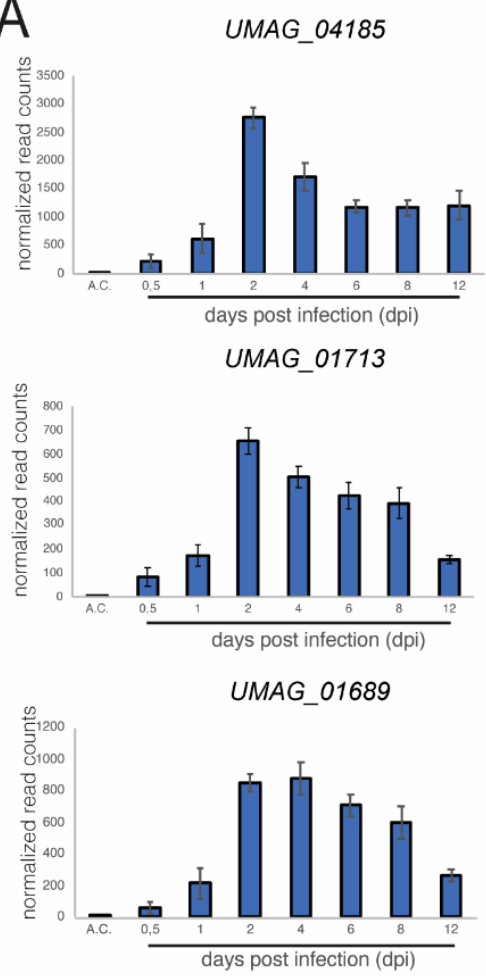

608
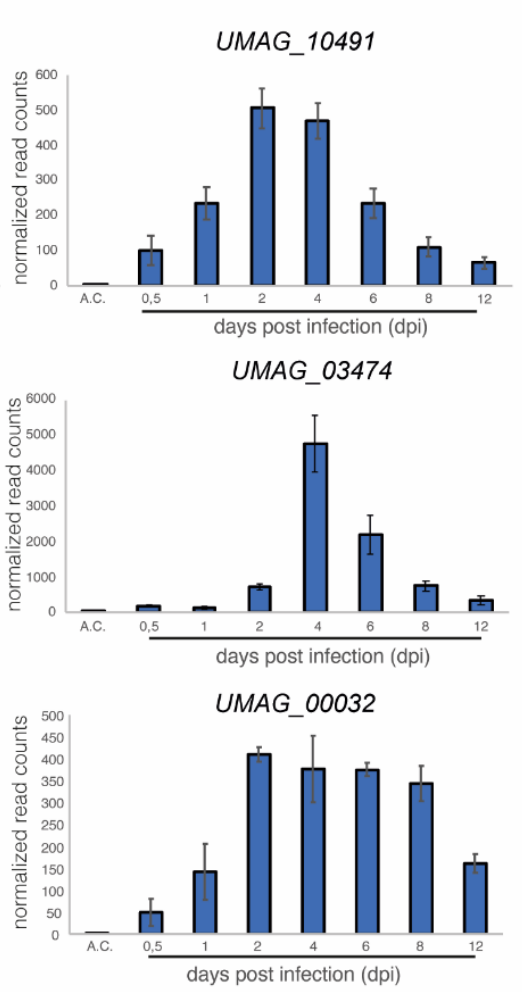

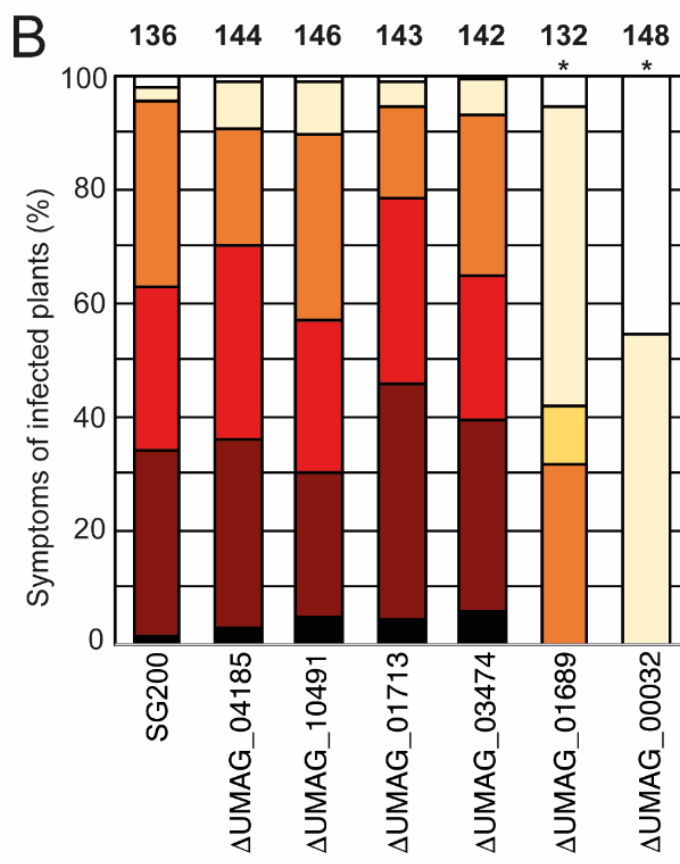

$\square$ No infection symptoms

$\square$ Ligula swelling

$\square$ Normal tumors

Dead plants

609 Figure 1. Identification of a transmembrane protein important for virulence. A. The expression pattern of genes encoding transmembrane proteins in U. maydis during plant infection re-analyzed from RNA sequencing data (Lanver et al. 2018). A.C., expression level in axenic culture. The numbers below the bars indicate the days post inoculation (dpi). Error bars indicate \pm SD. B.

613 Virulence assay of genes encoding transmembrane proteins in the U. maydis SG200 background. Disease symptoms were quantified on maize leaves 12 days post infection. Similar results were observed in three independent experiments. Shown is the mean percentage of plants placed in a particular disease category. The number of infected plants is indicated above the bars. The asterisk indicates a significant difference in infection symptoms between SG200, SG200 $\Delta$ vmp1 and

618 SG200ムvmp2. 


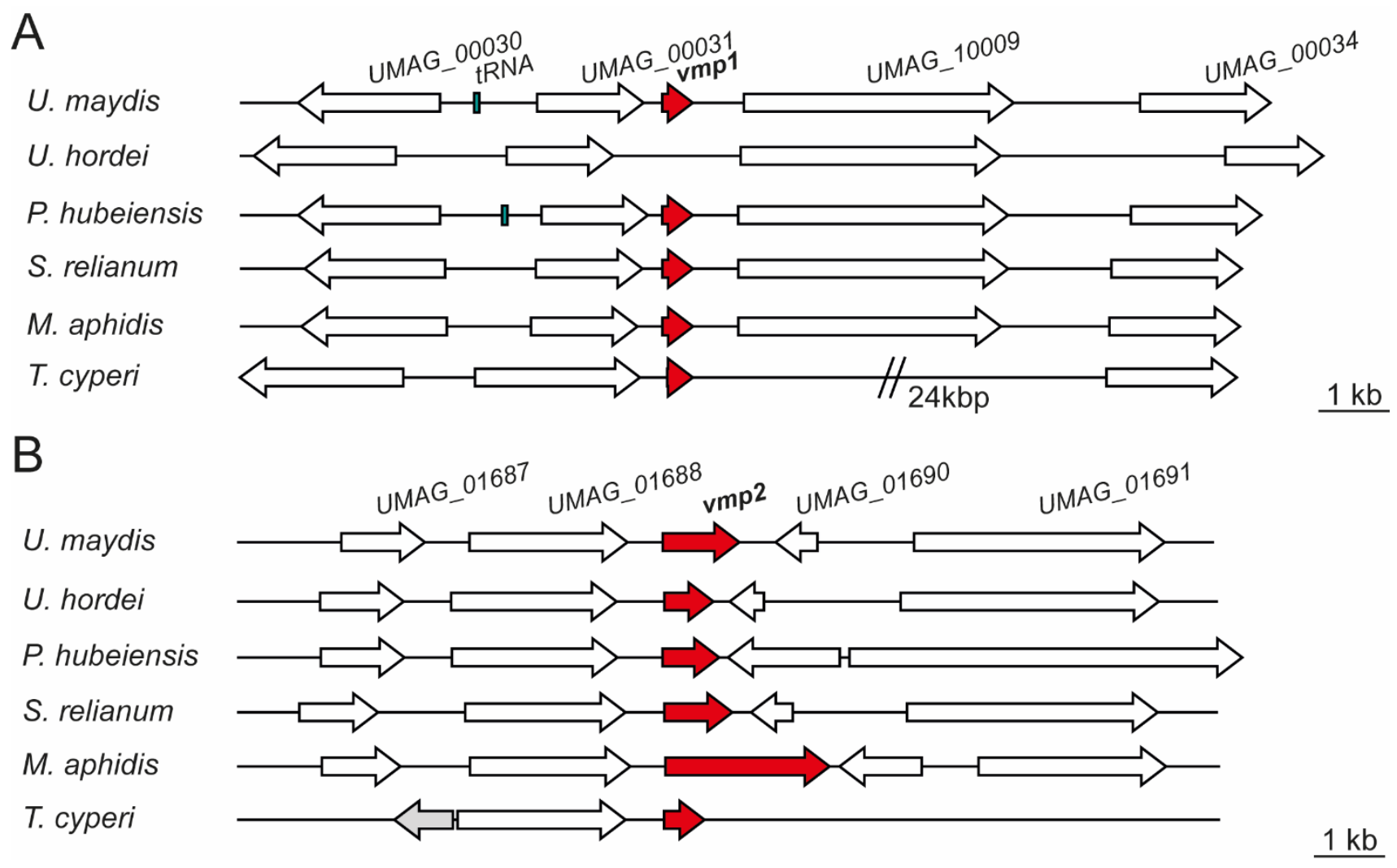

620 Figure 2. Vmp1 and Vmp2 orthologs are conserved in related smut fungi. Schematic picture of 621 gene loci encoding Vmp1 (A) and Vmp2 (B) and orthologs in the related smut pathogens Ustilago 622 hordei, Pseudozyma hubeiensis, Sporisorium relianum, Moesziomyces aphidis and Testicularia 623 cyperi. White arrows indicate genes found in all of the respective species, while the grey gene was 624 solely present in the genome of T. cyperi. 


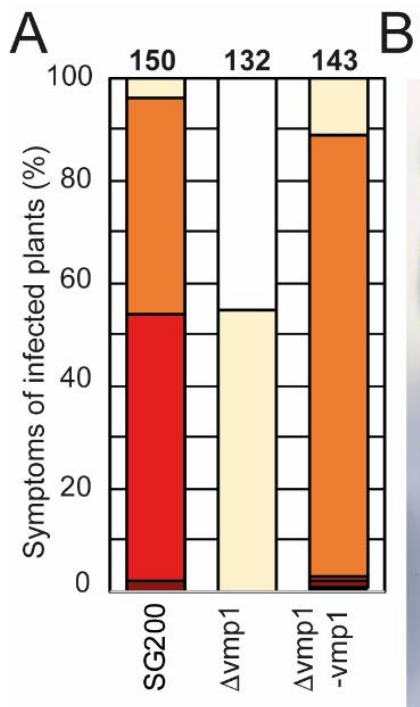

$\square$ No infection symptoms 口Chlorosis ¿ Ligula swelling $\square$ Small tumors $\square$ Normal tumors $\square$ Heavy tumors - Dead plants
C
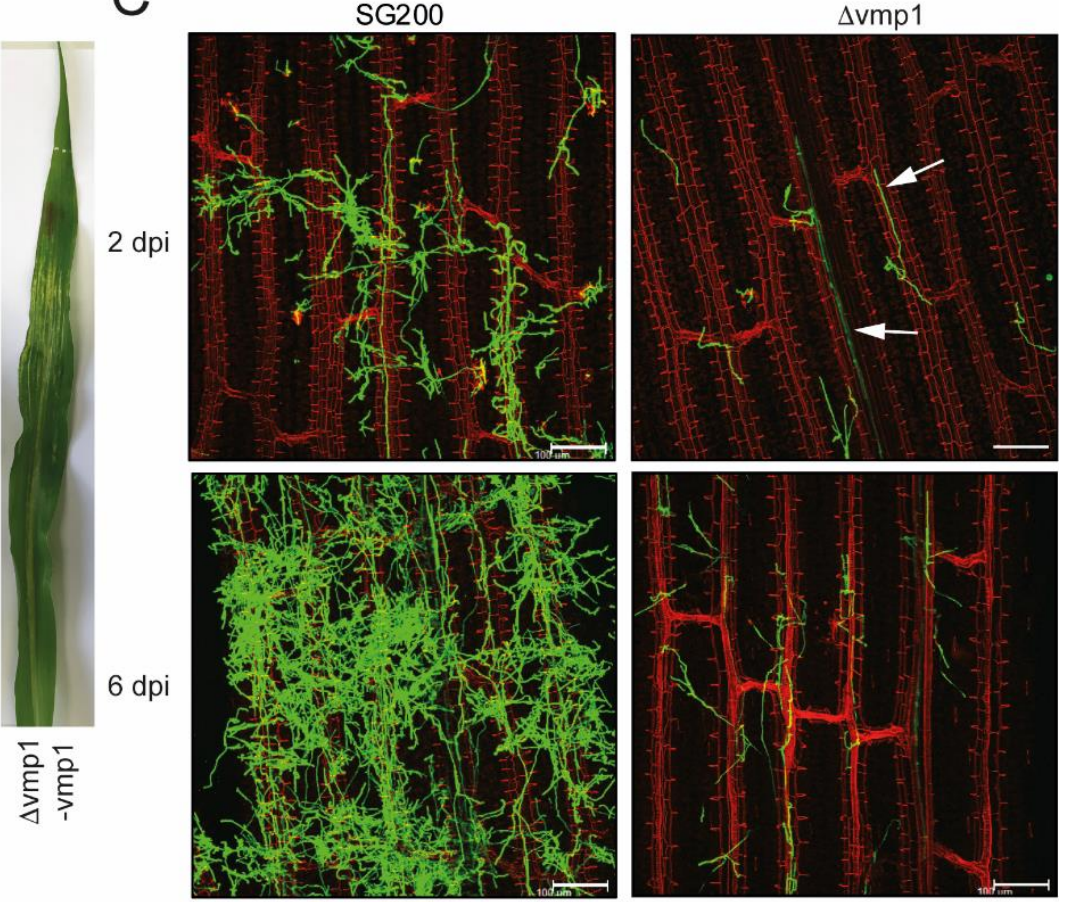

626 Figure 3. Vmp1 is required for virulence. A. Virulence assay of the SG200Avmp1 mutant strain 627 and SG200 $\Delta$ vmp1-vmp1 complementation strain in an U. maydis SG200 background. The mean 628 percentage of disease symptoms in the different categories is shown that were quantified based on 629 three biological replicates. The number of infected plants is indicated above the bars. B. Macroscopic 630 pictures of maize leaves 12 days post infection with $U$. maydis SG200, SG2004vmp1 and

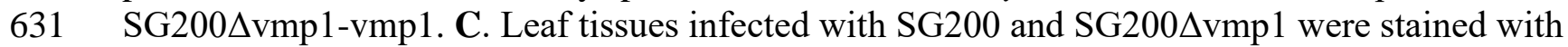
632 WGA-AF488 and propidium iodide at 2 and 6 dpi. Green color indicates fungal hyphae and red color 633 indicates leaf vascular bundles. Bar $=100 \mu \mathrm{m}$. 
A

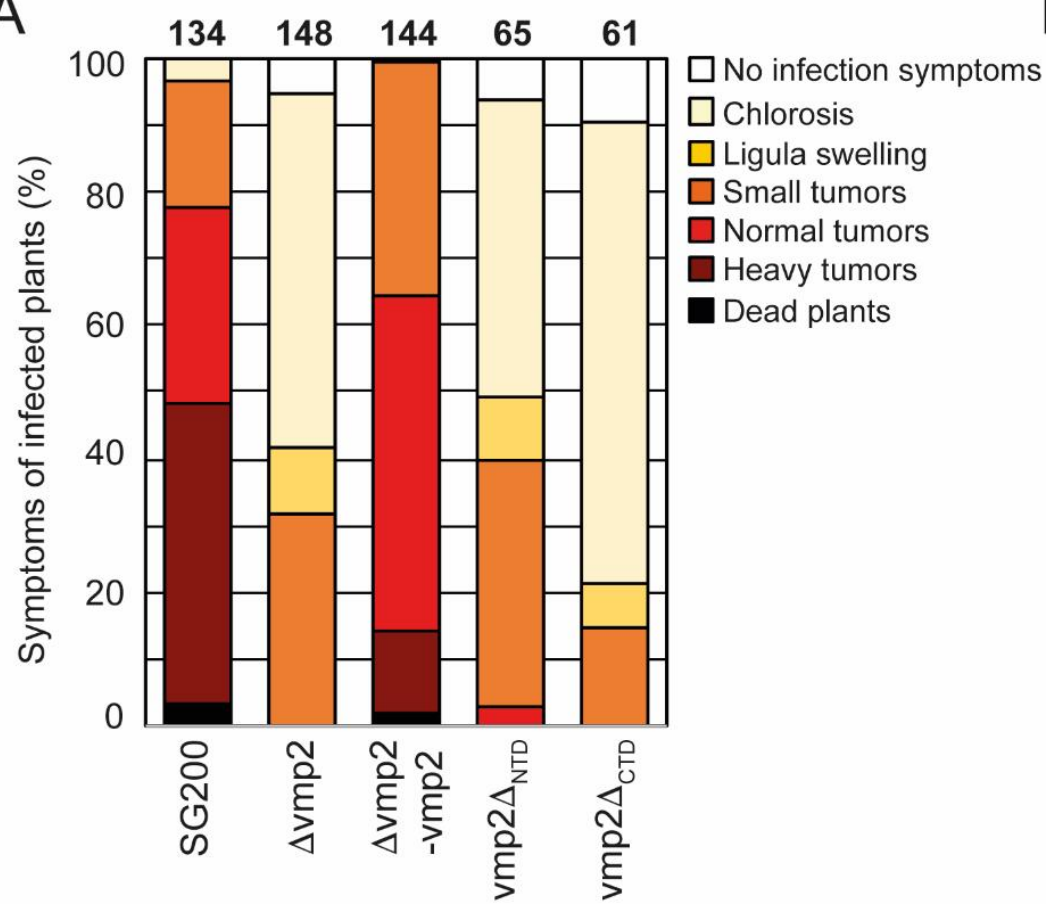

B
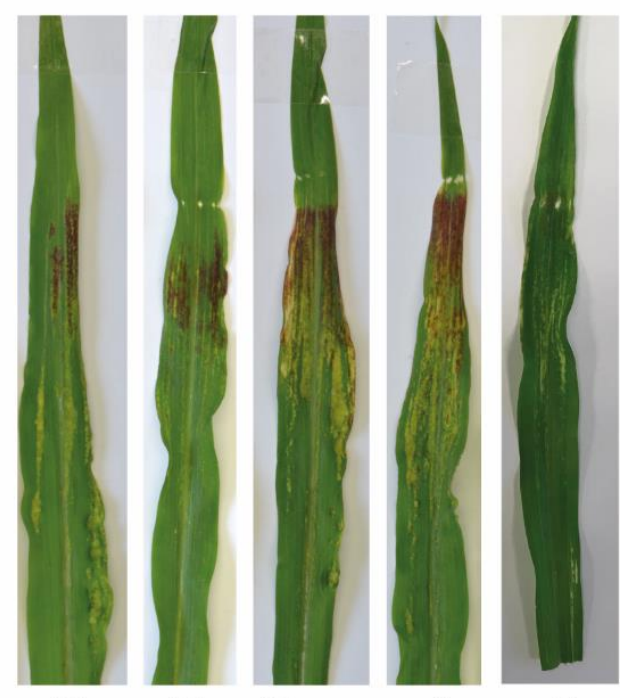

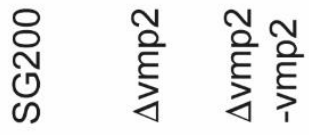

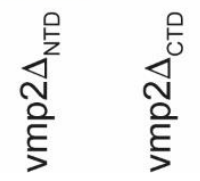

635 Figure 4. Vmp2 is required for virulence A. Virulence assay of the SG200 $\Delta \mathrm{vmp} 2$ mutant strain

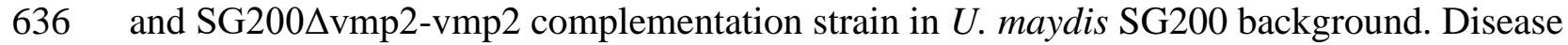
symptoms were quantified based on three biological replicates. The number of infected plants is

638 indicated above the bars. B. Macroscopic pictures of maize leaves infected by U. maydis SG200,

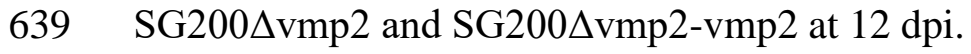


A molecular weight $(\mathrm{MW})$ in $\mathrm{kDa}$

6694401587544
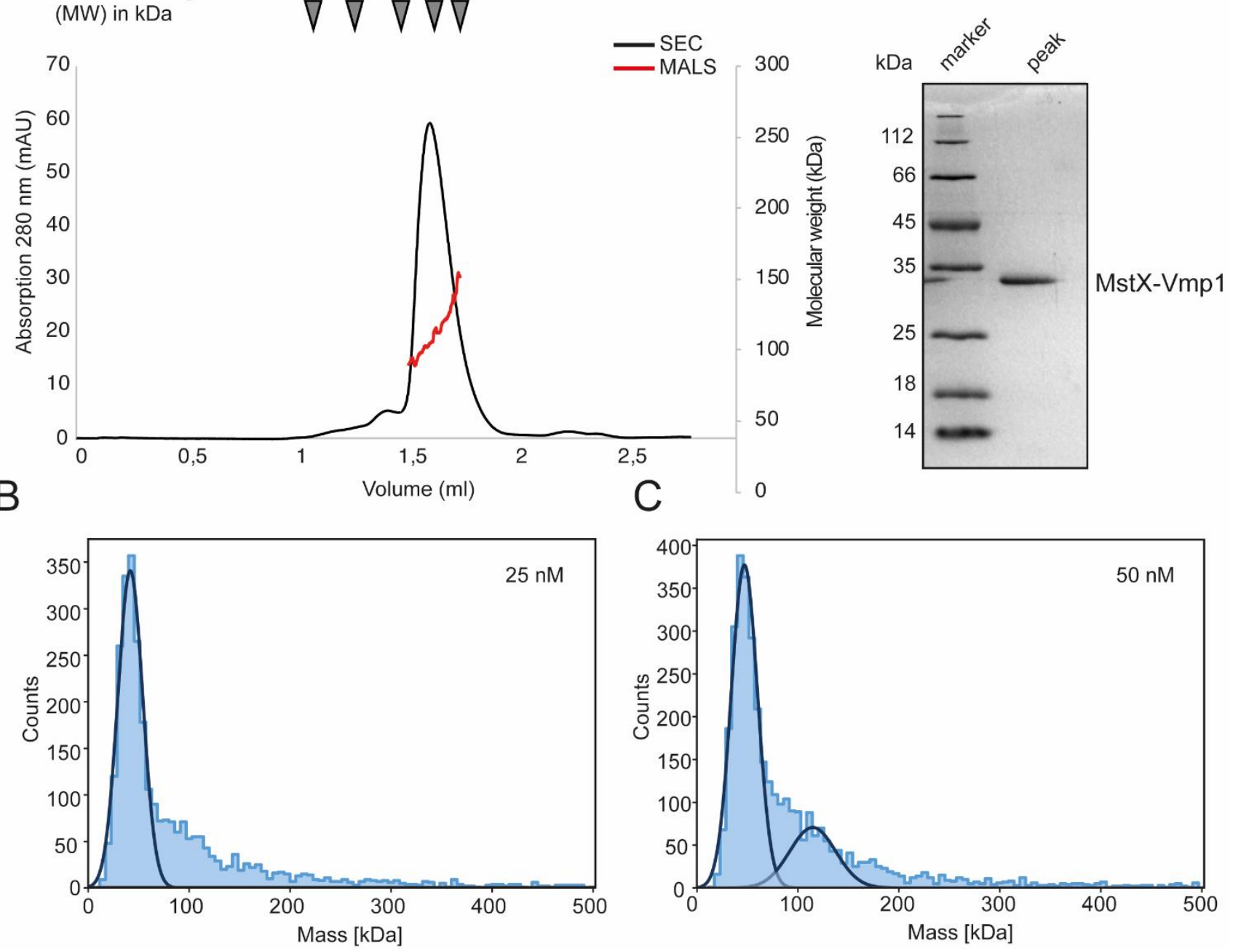

641 Figure 5. Biochemical analysis of Vmp1. A. Multi-angle-light scattering coupled size-exclusion 642

643 chromatography (SEC-MALS) of full length MstX-Vmp1. The black line depicts the absorption at $280 \mathrm{~nm}$, while the red line corresponds to the molecular weight as determined by MALS. The inset shows a SDS PAGE of the peak fraction. B and C. Mass photometry of Vmp2 in $0.1 \%$ LDAO at 25 and $50 \mathrm{nM}$ concentration, respectively. 
A

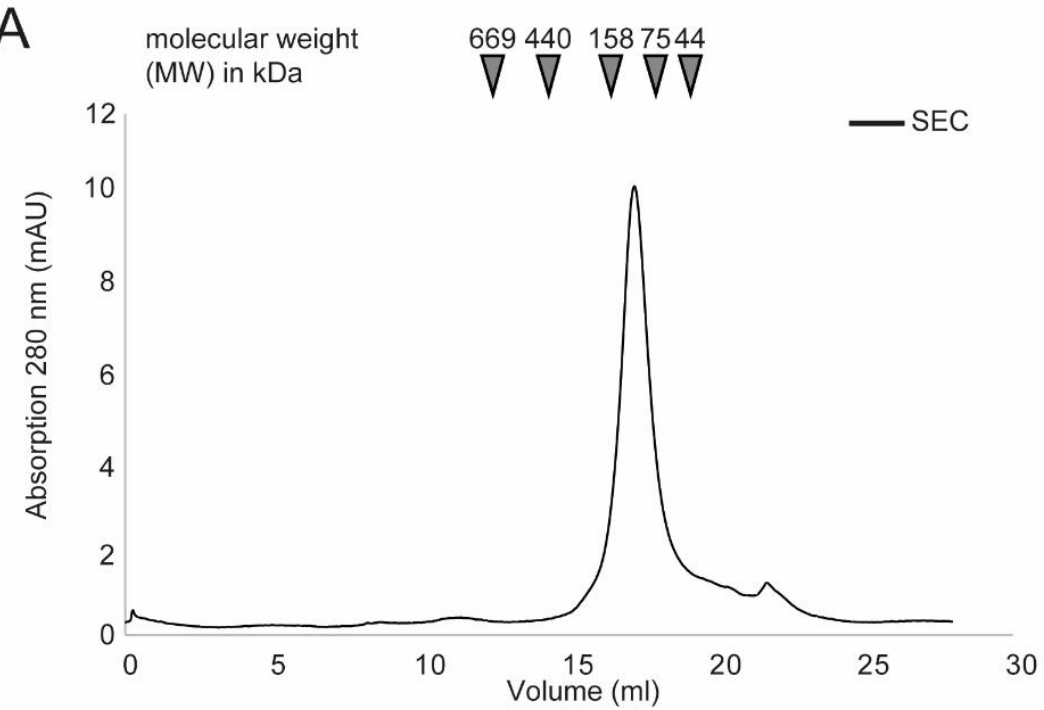

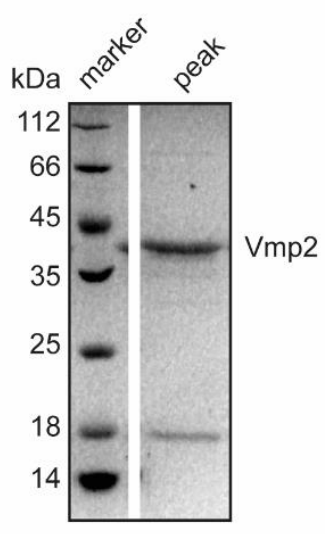

C

B
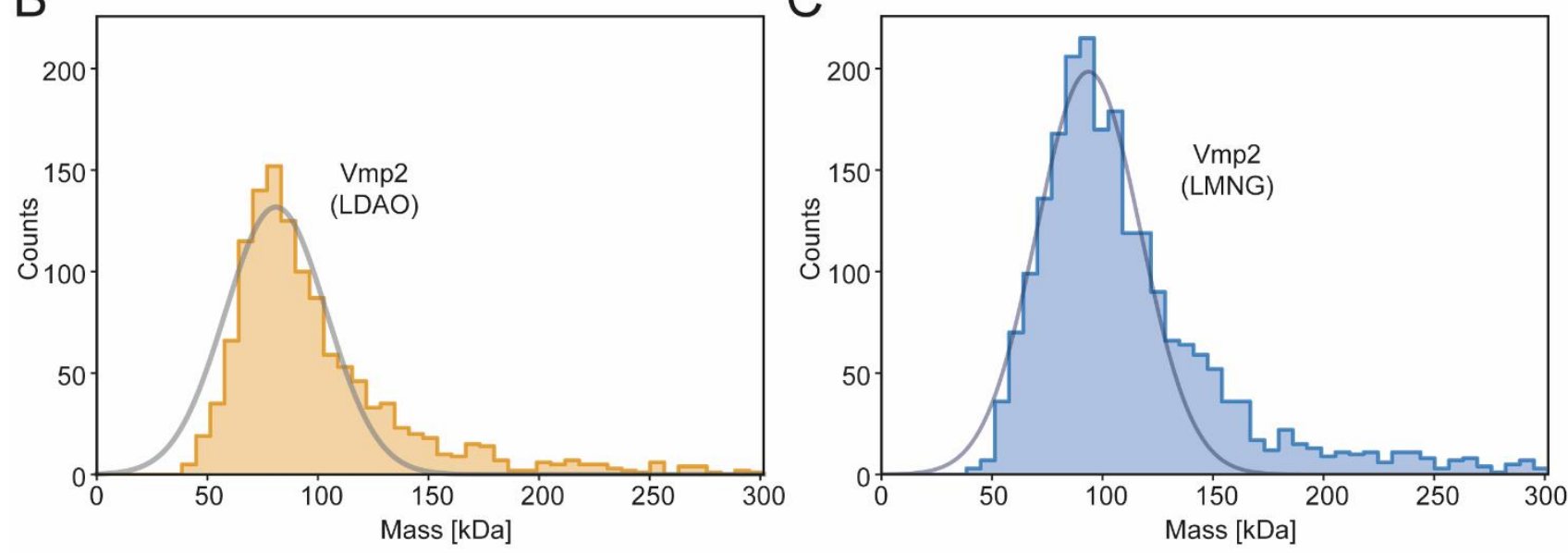

D molecular weight $442913,76,5$

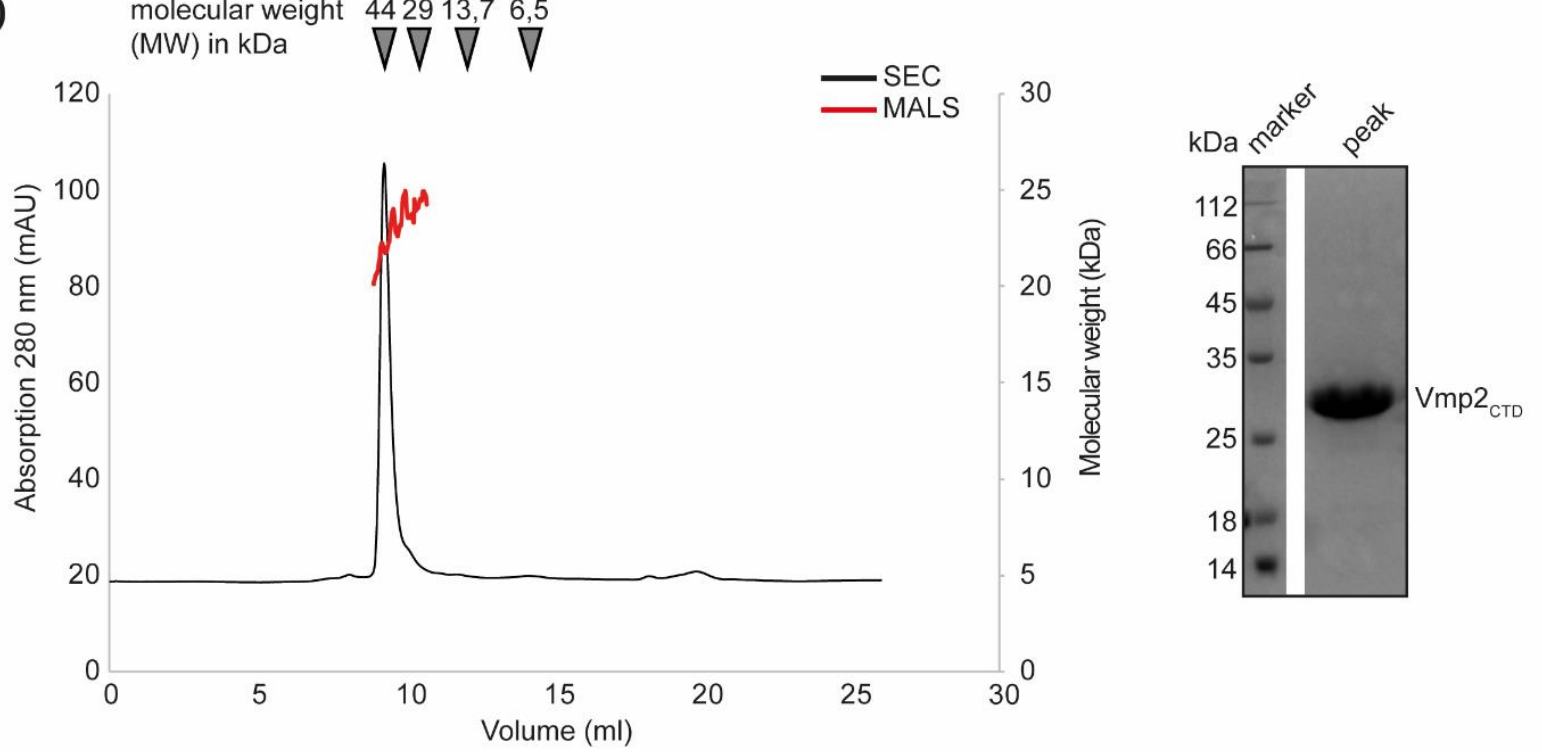

647 Figure 6. Biochemical analysis of Vmp2. A. SEC chromatogram of full length Vmp2. The inset
648 shows a SDS PAGE of the peak fraction. B. Mass photometry of Vmp2 in $0.1 \%$ LDAO. C. Mass

649 photometry of Vmp2 in $0.001 \%$ LMNG. D. Multi-angle-light scattering coupled size-exclusion

650 chromatography (SEC-MALS) shows that the C-terminal domain (CTD) of Vmp2 (aa 120 - 335) is 
bioRxiv preprint doi: https://doi.org/10.1101/2021.03.09.434588; this version posted March 10, 2021. The copyright holder for this preprint (which was not certified by peer review) is the author/funder. All rights reserved. No reuse allowed without permission.

Membrane-bound virulence factors

651 monomeric with an apparent molecular weight (MW) of $24 \mathrm{kDa}$. The black line depicts the

652 absorption at $280 \mathrm{~nm}$, while the red line corresponds to the molecular weight as determined by

653 MALS. The inset shows a SDS PAGE of the peak fraction. 